\title{
INTERNATIONAL BUSINESS NEGOTIATIONS IN A REGULATED AND INCOMPLETE INFORMATION MARKET
}

\author{
Kęstutis Peleckis ${ }^{1}$, Valentina Peleckiene் ${ }^{2}$, Bahman Peyravi ${ }^{3}$, Edita Leonavičiene் ${ }^{4}$ \\ ${ }^{1}$ Department of Economics Engineering, Faculty of Business Management, \\ Vilnius Gediminas Technical University, Sauletekio al. 11, LT-10223 Vilnius, Lithuania \\ ${ }^{2,3}$ Department of Management, Faculty of Business Management, \\ Vilnius Gediminas Technical University, Sauletekio al. 11, LT-10223 Vilnius, Lithuania \\ ${ }^{4}$ Department of Business Technologies and Entrepreneurship, Faculty of Business Management, \\ Vilnius Gediminas Technical University, Sauletekio al. 11, LT-10223 Vilnius, Lithuania \\ E-mails: ${ }^{1}$ k.peleckis@vgtu.lt (corresponding author); ${ }^{2}$ valentina.peleckiene@vgtu.lt; \\ ${ }^{3}$ bahman.peyravi@vgtu.lt; ${ }^{4}$ edita.leonaviciene@vgtu.lt
}

Received 28 February 2020; accepted 05 May 2020

\begin{abstract}
Regulations and government interventions often restrict competition in the market and rise certain challenges in business negotiations, when competition in the market is more or less distorted. Removing unnecessary restrains to competition and developing alternatives which still achieve the same policy objectives can bring substantial benefits for negotiation power of market business entities. Competition assessment is most effective when business negotiation entities have a clear sufficient information for comparing options, sufficient resources for conducting an analysis, and sufficient technical skills for performing the analysis. The aim of this article is to analyze in complex the unfolding theory and practice of development and implementation of business negotiating strategies in a regulated and incomplete information market, to reveal opportunities on development and implementing improvements of these strategies. Object of the research is the search of balance on negotiating powers in business negotiations in a regulated and incomplete information market. The scientific problem - negotiation theory lacks measures for assessment and balancing the negotiating powers between negotiation participants in a regulated and incomplete information market.
\end{abstract}

Keywords: negotiations, competition, market structure, competition assessment, market regulation, market power.

JEL Classification: D4, D9, F51.

\section{Introduction}

The economy is booming when markets are relatively competitive because it forces the business to be efficient and innovative. Longer-term effects on the national economy can result from better resource allocation, lower prices, better negotiations competitive position, and higher economic growth and prosperity. Traditionally, when drawing up regulations, governments usually neglect the effect of regulations on competition in the markets. While the effects of negotiations competition in the market cannot override some of the desired socioeconomic objectives pursued by the regulations, it is increasingly recognized that reducing the negative effects on competition can generate significant dividends. In recent years, many national governments have taken steps to assess the pros and cons of various rules and regulations in order to minimize economic growth and prosperity (Blume et al., 2018; Borne et al., 2018; Brooks \& Lesieutre, 2019; Cimon \& Garriott, 2019; Croutzet \& Lasserre, 2017; D'Aertrycke, Ehrenmann, \& Smeers, 2017; Denis, 2012; Gissey, Dodds, \& Radcliffe, 2018; Hu et al., 2018; Lee et al., 2018; Lohmann \& Trischler, 2017).

While initiatives to improve the effectiveness of regulations are gaining in popularity, there is relatively little guidance on how to assess the impact of various rules and regulations and government intervention on competition. Competition assessment, which focuses on assessing the impact of government policies and rules and restrictions imposed by professional organizations on market outcomes, can make a valuable contribution to improving the efficiency and effectiveness of rules and regulations and, to consumers, to higher economic welfare. Competition policy is the process by which governments try to promote competition and create a proper competitive environment by 
prohibiting or restricting certain types of business practices and negotiations that unduly restrict competition. In general, the objectives of competition policy can be considered as promoting competitive markets and innovation affecting prices, prosperity and economic growth.

The aim of this article is to analyse in complex the unfolding theory and practice of development and implementation of business negotiating strategies in a regulated and incomplete information market, to reveal opportunities on development and implementing improvements of these strategies. Object of the research is the search of balance on negotiating powers in business negotiations in a regulated and incomplete information market. The scientific problem - negotiation theory lacks measures for assessment and balancing the negotiating powers between negotiation participants in a regulated and incomplete information market. Research methods - scientific literature analysis, comparative, logical analysis and synthesis, comparative and generalisation methods.

\section{Availability of information in a regulated market}

There is always the pressing question of what activities should be undertaken as public services and which should be left to private companies. Many governments have opened state monopolies to private stakeholders (Maravillo et al., 2019; Motalleb, Annaswamy, \& Ghorbani, 2018; Moye-Holz et al., 2019; Murto et al., 2019; Niu et al., 2012; OECD, 2017a, 2017b, 2017c; Phillips \& Menkhaus, 2010; Pinto \& Falcão-Reis, 2019; Ren \& Zhang, 2014; Ritter et al., 2019; Willems \& De Corte, 2008; Yang, Zhang, \& Gao, 2019). It was covered for such industries as railways, highways, water, postal and telecommunications as well as education and health services. The experience of these privatizations has been mixed, and it has often been more difficult than expected to force private firms to behave in the desired way. There are two main difficulties.

First, in many markets dominate several firms, all of which in negotiations influence prices, volumes and quality. Traditional economic theory does not deal with this case, known as oligopoly, but presupposes a single monopoly, or called perfect competition. The second difficulty in negotiations is the lack of information on the costs and quality of the goods and services provided by the regulatory body. This lack of knowledge in negotiations often provides a natural advantage for regulated companies. In all countries, regulations have affected the prices of goods and services in markets such as electricity, cable TV, healthcare, telecommunications, airlines, taxis, rental housing. In the case of natural monopolies, the consequences of unregulated markets lead to undesirably high prices. Historically, this category has included industries such as electricity, telecommunications, natural gas, postal services and, inter alia, various forms of government price regulation to protect consumers from unreasonably high prices.

While governments may regulate prices to protect consumers, the negative side is that companies facing lower prices in negotiations than they would like to do may degrade the quality of service provided. Product diversity can also be reduced because existing companies may have little incentive to offer additional diversity through price control. In some countries, markets such as airlines, telecommunications, among other things, have seen changes in quality and variety as price rules have been softened. In addition, market entry may be reduced due to reduced profit incentives in markets where price regulation exists. In general, the literature shows that while governments may pursue legitimate social and economic objectives to control prices in certain markets, these controls can have a wide range of detrimental effects over time (Brooks \& Lesieutre, 2019; Cimon \& Garriott, 2019; Croutzet \& Lasserre, 2017).

When policy makers decide to intervene in the market, there are reasons to focus on "asymmetrically paternalistic" options that promote competition rather than imposing it, for example, price regulation. These tools can have significant benefits for consumers who make mistakes. Possible alternatives:

- providing user-friendly sources of comparative information (e.g. websites comparing average prices of mobile phone users from various existing offerings; food labeling requirements; labeling of in-store goods; requiring breakdown of estimates and invoices);

- standards for providing information to consumers (such as the general rule for calculating the annual percentage rate of charge) to improve the comparability of financing offers;

- postponement periods (a week to review the terms of a home loan; buying a car; surrendering consumer rights or door-todoor sales) that allow to save for users a time for getting more information and consideration; 
- disclosure requirements (for example, require mortgage lenders to provide an annual percentage rate and monthly payment).

It is not easy to improve information accessible to users. Users may suffer from information overload. Complex contracts written in a specific legal language can help to reduce the cost of resolving potential contractual disputes, but the language of such contracts and their disclosure can't help for ordinary users to make decisions. Sometimes providing the right information that can help negotiatiors agree on better deals can actually confuse their assessment of the attractiveness of different alternatives. It is difficult to ensure that users get the information they need in a timely manner, but improving the information available to users can bring great benefits to consumer welfare and potentially save huge sums.

\section{Influence of information exchange for busi- ness to compete}

Some rules, regulations, and mechanisms that allow negotiators to exchange information and collaborate on specific activities can create an environment that reduces incentives for business to compete. Of particular concern is that these circumstances may lead to cartel-like behavior, leading to higher prices, lost output and reduced diversity. These circumstances are very different from those related to the number and range of suppliers or business opportunities to compete. In addition, there are specific business practices that can be followed by firms from previously regulated industries, such as electricity, telecommunications and natural gas, which create barriers for negotiators to competition and reduce incentives to compete. Incentives to compete may be reduced in those cases when (Maravillo et al., 2019; Motalleb et al., 2018; Moye-Holz et al., 2019):

- creating self-regulatory or co-regulatory regimes;

- require or encourage publication of information; on suppliers' production, prices, sales or costs;

- national competition laws do not apply to the activities of a particular industry or group of suppliers;

- customer mobility between suppliers of goods or services is reduced by increasing explicit or implicit costs of switching suppliers.

It is of particular concern expenses experienced by dominant market players previously regu- lated. Many information exchange mechanisms and business collaboration are allowed, because they can help facilitate innovation and establish uniform technical codes, standards, and business practices. Companies and industries in many countries have been given a partial or total exemption from competition law to encourage their growth and increase exports. In some cases, economic and social objectives are justified, in other cases they may be wrong.

Self-regulation has a number of potential benefits (Blume et al., 2018; Borne et al., 2018; Brooks \& Lesieutre, 2019; Ritter et al., 2019; Willems \& De Corte, 2008; Yang et al., 2019):

- It provides an opportunity for more regulatory cooperation. Regulatory credibility may increase resulting from inclusion and endorsement of the respected industry association as an active participant in the regulatory system. These effects in turn can improve the level of compliance;

- Involves industry and other stakeholders in the regulatory process and enables the use of inexpensive resources or completely free, involving these countries in supervisory monitoring and, in some cases, enforcement activities.

- Participants in negotiations with specific knowledge are drawn to the design of the regulatory system, believing that it should be well adapted to its purpose and minimize formal regulation.

- Specific areas where self-regulation exists are:

- Product features, including quality and safety.

- Design Compatibility.

- Coordination of technical standards.

- Ethical standards of practice.

- Pollution control.

The fact that a formal regulatory process is avoided implies that self-regulation in its form and method is potentially more flexible than government regulation, and over time it is easier to change it according problems encountered.

\section{Impact of market regulation to the economy}

By limiting the number of suppliers there is a risk of creating market power and reducing competition in the negotiations (Willems \& De Corte, 2008; Yang et al., 2019). The market power of suppliers is an opportunity to increase the price profitably, reduce quality, or reduce innovation compared to levels that would prevail in a competitive market. 
With the decrease in the number of suppliers there is a risk of a reduction in competition (or collusion) between the remaining suppliers and can increase the ability of individual suppliers to raise prices. Reduced competition may reduce incentives to meet consumer needs effectively and may lead to lower innovation and long-term economic efficiency. Although politicians may have good reasons to limit the number or diversity of suppliers therefore the benefits of entry restriction must be carefully balanced with the fact that easy entry by new suppliers may prevent existing suppliers from exercising market power or by collusion.

Granting an exclusive right to produce a particular good or to provide a service implies the creation of a private monopoly. Historically, exclusive rights have often been granted under "natural monopoly". A monopoly exists when a good or service can reasonably be obtained from only one supplier. In a "natural monopoly", one supplier can produce the desired output more efficiently and at a lower cost than two or more suppliers. Exclusive rights, especially if granted over long periods of time, have often been seen as a means of stimulating large investments in infrastructure, which cannot happen without a guaranteed market incentive. However, sometimes exclusive rights are used in situations where they are not subject to the justification of a natural monopoly (Borne et al., 2018; Brooks \& Lesieutre, 2019; Cimon \& Garriott, 2019; Croutzet \& Lasserre, 2017; Ritter et al., 2019; Willems \& De Corte, 2008; Yang et al., 2019).

Exclusive rights are the greatest obstacle to market access and may lead to monopoly pricing and other problems related to the exercise of market power. Regulation does not always prevent these outcomes, as regulators are often unable to limit market power and protect consumers. Therefore, such rights should be limited and determined only after careful consideration of the taxable prices, the duration of the rights and the alternatives to achieve the same purposes.

In the absence of alternatives, regulators may consider auctioning of exclusive rights. In most cases, the division of exclusive rights between two or three parties can preserve the dynamics of competition to some degree in order to achieve the desired benefit. Entry is restricted by licenses or permits required for the activities. Qualification requirements may take the form of minimum standards for formal education and/or experience and may include requirements of a positive nature. In the financial field, for example, so-called aptitude tests are often required before taking up offi- cial positions at company and board level. In other industries, potential market participants sometimes have to perform a "public interest" test to show the "need" to provide additional services and, where appropriate, indicate that their arrival will not adversely affect the existing business (Moye-Holz et al., 2019; Murto et al., 2019; Niu et al., 2012; OECD, 2017a, 2017b, 2017c; Phillips \& Menkhaus, 2010; Pinto \& Falcão-Reis, 2019; Ren \& Zhang, 2014; Ritter et al., 2019; Willems \& De Corte, 2008; Yang et al., 2019).

In special cases can be fixed the number of license holders. License or permit requirements are often stricter than is needed for consumer protection and can unnecessarily reduce consumer choice or create artificial scarcity that raises prices. While licensing systems often have legitimate consumer protection objectives, such barriers often protect existing manufacturers from competition. Care must be taken to ensure that the requirements for licenses and permits do not become more burdensome than is necessary to achieve the desired regulatory objectives. Product quality standards ensuring consumer safety should not go beyond what is necessary. Similarly, restrictions on the size of suppliers should not be set at levels that have significant anti-competitive effects or inefficiencies. Similarly, when considering compulsory insurance, performance guarantees and similar requirements should be taken account of the nature and extent of the damage to the consumer, which may result from improper practices or failure of the service provider (Phillips \& Menkhaus, 2010).

In order to protect consumers from any possible harm, they must be able to accept reasonable decisions when choosing a service provider. There should be foreseen alternative methods to improve consumer knowledge. Rules that increase entry or exit costs will deter potential entrants, thereby reducing the number of entrants over time. Examples of this type of regulation include: stringent product testing requirements, unnecessarily high educational or technical qualifications to be followed.

Governments sometimes seek to minimize the negative effects of such provisions on competition by providing for targeted exemptions. For example, small car manufacturers are often exempt from or subject to vehicle testing regulations less burdensome test protocols. Alternatives such as providing additional information or considering product disclosure requirements could be used to better inform consumers before they make a choice. In some cases, regulation may be required, even if it could increase the entry price. The focus should be on minimizing the anti-competitive po- 
tential by ensuring that requirements are in place to ensure the necessary consumer protection at the minimum required level (OECD, 2017a, 2017b, 2017c; Ritter et al., 2019; Willems \& De Corte, 2008; Yang et al., 2019).

Legislation sometimes limits the flow of goods, services, capital and / or labor across jurisdictions, often as a tool of regional policy. However, such restrictions artificially reduce the geographical scope of competition in the provision of goods or services. This can reduce the number of suppliers and allow suppliers to exploit market power and increase prices. Possible limitations should be assessed on the following issues:

- Is there a clear link between the constraints and the achievement of specific policy objectives?

- Are restrictions necessary to achieve the goal?

- Does reasonable analysis indicate that the policy objective will be achieved through restraint measures?

- Are the restrictions limited to a defined period of time through explicit regulatory provisions?

There is a serious risk that "temporary" protection will become a near-permanent agreement, as a result of particular lobbying by suppliers, who will benefit from restrictions. Regulation can affect a supplier's ability to compete in a variety of ways, including: restrictions on advertising and marketing; standard measurement of product or service quality; control of prices of goods and services. These limits may reduce the intensity and dimensions of competition, lead to higher prices for consumers and lower product diversity. Governments often regulate prices in traditionally monopolistic sectors such as utilities services (OECD, 2017a, 2017b, 2017c; Phillips \& Menkhaus, 2010; Pinto \& Falcão-Reis, 2019; Ren \& Zhang, 2014; Ritter et al., 2019; Willems \& De Corte, 2008; Yang et al., 2019). These types of price controls are probably beneficial to consumers and serve as a counterweight to the lack of consumer alternatives.

However, price control is sometimes applied when there are many potential suppliers for the same customer. When minimum prices are set for low-cost suppliers that provide better value to consumers then it prevents them from winning market share. Similarly, setting maximum prices can significantly reduce incentives for suppliers to innovate with new and / or high quality products, and allow suppliers to effectively align their prices at maximum prices.
Minimum price regulation is sometimes a response to extreme price competition. In such cases, minimum price regulation is generally seen as a means of protecting small suppliers from "unfair" competition. The impact of such price regulation is well worth considering, as it is likely to be the result of higher prices for consumers or unmet demand. Maximum prices are set often as a necessary consequence of market entry restrictions. The alternative is allowing more free access to the market. Price regulation is rarely the most effective or efficient means of achieving the intended objectives. For example, in the taxi market, the removal of supply restrictions by introducing roadside surveillance services is a better measure for consumer protection. As far as predatory pricing is concerned, general competition law is likely to be a better alternative. So regulation offering price control should be particularly strict checked (Lee et al., 2018; Lohmann \& Trischler, 2017; Maravillo et al., 2019; Motalleb et al., 2018; Moye-Holz et al., 2019).

It is important to recognize the different types of new entrants in order to understand their impact on market entry. There are three broad types of entry players. New enterprise involved in the construction of a new plant (production facility) in the manufacturing sector or similar in the services sector. For example, a new machine tool company started entrepreneurs with no prior business experience. Information technology revolution and the influx of biotechnology and nano-technology has realized that many firms are entering these industries and have no prior business experience in these or other industries. New graduate legal practice would also fall into this category.

Diversification of the business through changes in the variety of products they produce in existing factories. For example, a car company that has historically produced mid-size and large cars produces small fuel efficient cars in the same flexible manufacturing plant. Steel company producing machined steel and alloy steel diversifies the production of steel bearings and gears. A software company that focused on network security software is diversifying into online games. Overall, previous business experience allows entrepreneurs to learn from past experience, knowledge of markets, and regulatory barriers (D'Aertrycke et al., 2017; Denis, 2012; Gissey et al., 2018; Hu et al., 2018).

In general, previous business experience allows entrepreneurs to learn from previous experience, knowledge about markets and regulatory barriers. Failure (or departure) rates are usually quite high and: 
- generally, more than $60 \%$ of those entering one group fail and leave the industry within five years;

- type 1 market participant (new company with new plant) exit rates are 7-8 times higher than type 2 participants (diversifying company with new company).

If success in the market negotiations is risky, in any case, new entrants incur high exit costs, acting as an additional entry barrier and discouraging entry.

\section{Indirect ways of regulating the market}

Market access is restricted by various rules and regulations set by governments and professional organizations. Regulations can take very clear forms, such as total entry restrictions, but they can also be indirect. Explicit restrictions are direct and have the greatest negative impact on competition. Many countries have rules regarding the number of retail stores that may be allowed in a particular geographic area or for a certain number of people living in an area.

There are implied restrictions which indirectly restricts the entrance to the market. For example:unregulated telecommunications markets to facilitate competition rules would be needed to force the market to share its network with new entrants. In addition, participants cannot provide (decent) services (online, over the phone) and compete. Similar problems arise in electricity markets where necessary to enter the market to the incumbent's transmission network in order to have significant competition. However, the non-sharing obligation does not necessarily mean that the incumbent will not allow access to its network, but it will nevertheless do so for the entrant/potential competitor becomes a more uncertain business outlook (Yang et al., 2019):

- quality standards and certification rules, including those adopted by professional organizations such as legal, accounting, or medical, can impose severe entry barriers.

- large administrative and bureaucratic obstacles can delay entry or hinder entry.

While in many cases the initial justification for rules and regulations in the public interest was well founded, it is important to keep in mind that they may adversely affect consumer welfare and slow down the long-term growth and development of markets. The market access restrictions should be avoided, in particular those related to the regulation of the market structure.
However, regulations such as those based on land use regulations under certain circumstances, may be considered reasonable. In the case of a natural monopoly and, for example, in the context of universal service, exclusive rights should not be part of the agreement. If they will be included to the agreement, they should be reviewed and amended because of changes in circumstances and market conditions. In such circumstances, when countries apply entry restrictions based on stability considerations, such as financial markets and banking, what should be done should be clear and transparent, and the principle of minimum restrictions should apply. In view of the potentially significant adverse effects, any rules or regulations that result in explicit or implicit scrutiny must be carefully considered by regulators entrance restrictions.

\section{Grant or extension of exclusive rights}

Governments give business exclusive rights to ideas, production of goods, purchase of goods and provision of services in many areas. For example:

- in solid waste disposal markets a common waste collection mechanism for local markets has been provided by a private company, which has exclusive rights to collect waste.

- in the past, for example, electricity, natural gas, telecommunications, water, postal services and railways have been granted a legal monopoly or exclusive rights to provide services;

- in various markets and countries, local, regional or national government agencies may sign contracts that grant exclusive rights to private companies to supply specific goods and services. This can occur through defense contracts, supply of raw materials. There are many reasons for granting or extending exclusive rights. In some industries, one of the reasons for granting legitimate monopolies (or exclusive rights) is the economies of scale that result from high overheads. Over time, as markets and technology evolved, many countries deregulated, privatized national companies and allowed them to compete (Blume et al., 2018; Borne et al., 2018).

In addition, more sophisticated regulatory approaches have allowed the identification of industry-specific elements, which are subject to natural monopoly, and distinguished them from other potentially competitive elements (both upstream and 
downstream). Recipients of exclusive rights to the production of goods and services are gaining significant market power. In the case of natural monopolies the problem has been alleviated according to price or rate of return in the utilities industry. There are clear justifications for granting patents, but one topic that has caused much debate and concern is the "extension" of patents. For example, pharmaceutical companies have aggressively tried to extend patents. Extending patent protection periods may have significant disadvantages:

- it extends the period during which consumers will pay higher prices;

- patent owners can aggressively fight for extension of potential market participants, such as generic companies, incur high costs (such as litigation costs) and can significantly reduce the likelihood of future market entry. The long-term negative effects on competition can be significant.

Although the granting of legal monopolies had a sound rationale, the regulatory impact literature shows that there were significant shortcomings in terms of lack of innovation, inefficiencies in production and introduction of newer technologies, which were detrimental to the long-term growth of these industries. In other cases where governments grant exclusive rights, the pros and cons. are unequal and are best evaluated on a case-by-case basis. In the solid waste disposal example above governments are increasingly aware that they can allow competition in these markets and have a positive impact (Lohmann \& Trischler, 2017; Maravillo et al., 2019).

In many cases exclusive rights, granted by the government, can be removed together with close observation of these markets. The evidence is growing that granting or extending exclusive rights in certain areas does not necessarily improve welfare. For example, given the growing popularity of generic drugs patent extensions need to be examined very carefully. There are, of course, cases where there should be granted extensions, such as when protracted regulatory enactments continue approval process which greatly shortens the term of the patent. In some cases, patent owners may aggressively raise prices and charge high costs for generic manufacturers. Some incumbents have deep pockets and may engage in long litigation, and competitors may not always have the ability to do so. In such cases, the extension of the patent may prevent consumers from purchasing cheaper generic medicines and impair their well-being. In several other areas, such as waste collection, several experiments leading to more competition in the markets show a marked increase in the quality and cost of the services provided. Generally speaking, the granting or extension of exclusive rights must be carefully considered as it may significantly reduce competition (Lee et al., 2018; Lohmann \& Trischler, 2017).

Historically, tolls have been applied to the movement of goods across different regions and states. Although over time many of these restrictions have been abolished, there are still cases where they persist. The arguments for establishing such rules are mixed and includes:

- protection of state or regional companies from competition;

- charges have been levied on the weight of the goods and the size of trucks from other regions and states that could move through that region or state, since the roads in the region or state are usually the responsibility of the local government;

- consumer protection, for example, through the adoption of laws prohibiting the sale of non-state/regional alcohol in a particular state or to transport alcohol through or to that state.

Legislation restricting the geographical flow of goods can take very clear forms, such as a direct ban on the purchase of goods and services from outside the country or region (Willems \& De Corte, 2008; Yang et al., 2019). It is important to recognize the free movement of goods, services and capital through the regions of the country, is essential for consumers to take advantage of the competition and for businesses to access wider markets to sell and grow. These advantages can be lost if the regions or states of the countries will legalize flows of goods and services. This means that proposed rules and regulations that restrict the flow of goods and services should be carefully checked and assessed their expected benefits, costs and impact on competition. Usually such restrictions should be removed.

Governments and professional organizations can establish rules and regulations for which sometimes may decrease competition in the negotiations between companies in the market, prices may rise and decrease variety and quality of goods and services.

\section{Conclusions}

It is not simple to improve information accessible to users. Negotiators may suffer from information overload. Complex contracts written in a specific legal language can help reduce the cost of resolv- 
ing potential contractual disputes, but the language of such contracts and their disclosure cannot help ordinary users to make decisions. Sometimes providing the right information which could help negotiatiors agreeing on better deals may actually confuse their assessment of the attractiveness of different alternatives. It is difficult to ensure that consumers receive the information they need in a timely manner, but improving the content of the information available to consumers can bring significant benefits to consumers' wellbeing and potentially save significant amounts.

Some rules, regulations, and mechanisms that allow companies to exchange information and collaborate on specific activities can create an environment that reduces incentives for business to compete. Of particular concern is that these circumstances may lead to cartel-like behavior, leading to higher prices, lost output and reduced diversity. These circumstances are very different from those related to the number and range of suppliers or business opportunities to compete. Of particular concern is the expenditures experienced by dominant market players, which were previously regulated.

Many information exchange mechanisms and negotiators collaboration are allowed, because they can help facilitate innovation and establish uniform technical codes, standards, and business practices. For companies and industries in many countries a partial or total exemption has been (is) granted from competition laws to encourage their growth and increase exports. In some cases, economic and social objectives can be justified, in other cases they may be wrong. The fact that a formal regulatory process is avoided means that self-regulation in its form and method is potentially more flexible, than governmental regulation, and that it is easier to change over time as problems arise.

The exclusive rights in many aspects are major barrier for the negotiatiors to entry and can lead to monopoly pricing and other problems related to the exercise of market power. Regulation does not always prevent these outcomes, as regulators are often unable to limit market power and protect consumers. Therefore, such rights should be limited and determined only after careful consideration of the taxable prices, the duration of the rights and the alternatives to achieve the same goals. In the absence of alternatives, regulators may consider auctioning exclusive rights. In many cases, the division of exclusive rights between two or three parties can preserve the dynamics of competition to some degree in order to achieve desired benefits.
The entry to the market is restricted by licenses or permits required for the activities.

Qualification requirements may take the form of minimum standards for formal education and / or experience and may include requirements of a positive nature regulation of minimum prices is sometimes a response to extreme price competition in the negotiations. In such cases, minimum price regulation is generally seen as a means of protecting small suppliers from "unfair" competition. The effect of such price regulation needs to be carefully evaluated, as higher prices to consumers or unmet demand are likely to result. Maximum prices are often set as a necessary consequence of entry restrictions. The alternative is to let more freely to enter the market. Price regulation is rarely the most effective or efficient means of achieving the intended objectives.

Legislation restricting the geographical flow of goods can take very clear forms, such as a direct ban on the purchase of goods and services from within a country or region. It is important to recognize that the free movement of goods, services and capital across regions of the country is crucial for consumers to reap the benefits of competition and for businesses to gain access to wider markets to sell and grow. These advantages can be lost if the regions or states of the countries will legitimize flows of goods and services. This means that the proposed rules and regulations restricting the flow of goods and services should be closely scrutinized and assessed their expected benefits, costs and impact on competition.

\section{References}

Blume, L., Cogley, T., Easley, D., Sargent, T., \& Tsyrennikov, V. (2018). A case for incomplete markets. Journal of Economic Theory, 178, 191221. https://doi.org/10.1016/j.jet.2018.09.004

Borne, O., Korte, K., Perez, Y., Petit, M., \& Purkus, A. (2018). Barriers to entry in frequency-regulation services markets: Review of the status quo and options for improvements. Renewable and Sustainable Energy Reviews, 81(1), 605-614. https://doi.org/10.1016/j.rser.2017.08.052

Brooks, E., \& Lesieutre, B. (2019). A review of frequency regulation markets in three U.S. ISO/RTOs. The Electricity Journal, 32(10). https://doi.org/10.1016/j.tej.2019.106668

Cimon, D., \& Garriott, C. (2019). Banking regulation and market making. Journal of Banking \& Finance, 109. https://doi.org/10.1016/j.jbankfin.2019.105653

Croutzet, A., \& Lasserre, P. (2017). Optimal completeness of property rights on renewable resources in 
the presence of market power. Resource and Energy Economics, 49, 16-32.

https://doi.org/10.1016/j.reseneeco.2017.03.004

D’Aertrycke, G. M., Ehrenmann, A., \& Smeers, Y. (2017). Investment with incomplete markets for risk: The need for long-term contracts. Energy Policy, 105, 571-583. https://doi.org/10.1016/j.enpol.2017.01.029

Denis, D. K. (2012). Mandatory clawback provisions, information disclosure, and the regulation of securities markets. Journal of Accounting and Economics, 54(2-3), 197-200. https://doi.org/10.1016/j.jacceco.2012.07.002

Gissey, G., Dodds, P., \& Radcliffe, J. (2018). Market and regulatory barriers to electrical energy storage innovation. Renewable and Sustainable Energy Reviews, 82(1), 781-790. https://doi.org/10.1016/j.rser.2017.09.079

$\mathrm{Hu}$, J., Harmsen, R., Crijns-Graus, W., Worrell, E., \& van den Broek, M. (2018). Identifying barriers to large-scale integration of variable renewable electricity into the electricity market: A literature review of market design. Renewable and Sustainable Energy Reviews, 81(2), 2181-2195. https://doi.org/10.1016/j.rser.2017.06.028

Lee, A., Loschelder, D., Schweinsberg, M., Mason, M., \& Galinsky, A. (2018). Too precise to pursue: How precise first offers create barriers-to-entry in negotiations and markets. Organizational Behavior and Human Decision Processes, 148, 87-100. https://doi.org/10.1016/j.obhdp.2018.03.001

Lohmann, G., \& Trischler, J. (2017). Licence to build, licence to charge? Market power, pricing and the financing of airport infrastructure development in Australia. Transport Policy, 59, 28-37. https://doi.org/10.1016/j.tranpol.2017.06.009

Maravillo, H., Camacho-Vallejo, J., Puerto, J., \& Labbé, M. (2019). A market regulation bilevel problem: A case study of the Mexican petrochemical industry. Omega (in Press). https://doi.org/10.1016/j.omega.2019.08.012

Motalleb, M., Annaswamy, A., \& Ghorbani, R. (2018). A real-time demand response market through a repeated incomplete-information game. Energy, 143, 424-438. https://doi.org/10.1016/j.energy.2017.10.129

Moye-Holz, D., van Dijk, J., Reijneveld, S., \& Hogerzeil, H. (2019). The impact of price negotiations on public procurement prices and access to 8 innovative cancer medicines in a middle-income country: the case of Mexico. Value in Health Regional Issues, 20, 129-135.

https://doi.org/10.1016/j.vhri.2019.04.006

Murto, P., Jalas, M., Juntunen, J., \& Hyysalo, S. (2019). The difficult process of adopting a comprehensive energy retrofit in housing companies: Barriers posed by nascent markets and complicated calculability. Energy Policy, 132, 955-964. https://doi.org/10.1016/j.enpol.2019.06.062

Niu, Y., Dong, L., \& Chen, R. (2012). Market entry barriers in China. Journal of Business Research, 65(1), 68-76. https://doi.org/10.1016/j.jbusres.2011.01.018

OECD. (2017a). Competitions assessment toolkit, 1 (54 p.). www.oecd.org/competition/toolkit

OECD. (2017b). Competitions assessment toolkit, 2 (54 p.). www.oecd.org/competition/toolkit

OECD. (2017c). Competitions assessment toolkit, 3 (54 p.). www.oecd.org/competition/toolkit

Phillips, O., \& Menkhaus, D. (2010). The culture of private negotiation: Endogenous price anchors in simple bilateral bargaining experiments. Journal of Economic Behavior \& Organization, 76(3), 705715. https://doi.org/10.1016/j.jebo.2010.08.004

Pinto, T., \& Falcão-Reis, F. (2019). Strategic participation in competitive electricity markets: Internal versus sectorial data analysis. International Journal of Electrical Power \& Energy Systems, 108, 432-444. https://doi.org/10.1016/j.ijepes.2019.01.011

Ren, F., \& Zhang, M. (2014). A single issue negotiation model for agents bargaining in dynamic electronic markets. Decision Support Systems, 60, 55-67. https://doi.org/10.1016/j.dss.2013.05.020

Ritter, G., Walkinshaw, L., Quinn, E., Ickes, S., \& Johnson, D. (2019). An assessment of perceived barriers to farmers' market access. Journal of $\mathrm{Nu}$ trition Education and Behavior, 51(1), 48-56. https://doi.org/10.1016/j.jneb.2018.07.020

Willems, B., \& De Corte, E. (2008). Market power mitigation by regulating contract portfolio risk. Energy Policy, 36(10), 3787-3796. https://doi.org/10.1016/j.enpol.2008.07.008

Yang, X., Zhang, Z., \& Gao, X. (2019). Asian-barrier option pricing formulas of uncertain financial market, Chaos. Solitons \& Fractals, 123, 79-86. https://doi.org/10.1016/j.chaos.2019.03.037 